\title{
PREVALENCIA DE FALLA EN LA TRANSFERENCIA DE INMUNIDAD PASIVA EN TERNERAS DE LECHERÍA ${ }^{1}$
}

\author{
Juan José Arroyo-Arroyo², Jorge Alberto Elizondo-Salazar²
}

\begin{abstract}
RESUMEN
Prevalencia de falla en la transferencia de inmunidad pasiva en terneras de lechería. El objetivo del presente estudio fue determinar por tercer año consecutivo, la falla en la transferencia de inmunidad pasiva en terneras de lechería en la Región Huetar Norte de Costa Rica. Los datos presentados corresponden a determinaciones de la concentración de proteína sérica total (PST) obtenidos durante el periodo comprendido entre agosto y noviembre del 2012, en veintitrés fincas lecheras. Fueron evaluadas 657 terneras. Las razas de las vacas se clasificaron en Holstein, Jersey, cruce Holstein $\times$ Jersey y otras. Para fines del presente estudio, se consideró una falla en la adquisición de inmunidad pasiva cuando la concentración de PST fue menor a 5,5 g/dl. La concentración de PST varió entre 2,4 y 10,0 g/dl, con un promedio general de $5,7 \mathrm{~g} / \mathrm{dl}$. De todos los animales evaluados un $44,9 \%$ presentaron falla en la transferencia de inmunidad pasiva. Los animales provenientes de la raza Jersey y del cruce Holstein $\times$ Jersey, obtuvieron una concentración significativamente mayor a los de la raza Holstein y otras razas. Al considerar el número de parto de la madre, no se encontraron diferencias significativas en la concentración de PST de las crías. Sin embargo, las crías de vacas de tercer parto presentaron la menor proporción de terneras con niveles inadecuados de inmunidad. Es necesario establecer prácticas de manejo del calostro que permitan minimizar el riesgo de terneras con una transferencia de inmunidad pasiva inadecuada en hatos lecheros de la región Huetar Norte de Costa Rica.
\end{abstract}

Palabras clave: proteína sérica total, inmunoglobulinas, ganado de leche.

\begin{abstract}
Defective transmission of passive immunity in dairy farm calves. The objective of this study was to determine the prevalence of failure of passive transfer of immunity of dairy heifer calves for the third consecutive year in the Northern Plains of Costa Rica. The data correspond to total serum protein (TSP) measurements obtained during the period of August and November of 2012 in 23 dairy farms. 657 female calves were sampled. The breeds of the cows were classified into Holstein, Jersey, Holstein $\times$ Jersey crosses and others. For the purpose of this study, failure of passive immunity was considered when TSP concentration was less than $5.5 \mathrm{~g} / \mathrm{dl}$. TSP concentration ranged from 2.4 to 10.0 , with an overall mean of $5.7 \mathrm{~g} / \mathrm{dl}$. Of all the calves evaluated, $44.9 \%$ presented failure of passive transfer. Calves born to Jersey and Holstein x Jersey crosses had significantly higher TSP concentrations than calves born to Holstein and other breeds. When considering calving of the dam, there were no significant differences on TSP concentration, however offsprings born to third lactation cows showed the lowest percentage of animals with inadequate transfer of immunity. The findings of this study suggest that colostrum management practices should be placed in order to minimize the risk of failure of passive transfer of immunity in dairy herds in the Northern Plains of Costa Rica.
\end{abstract}

Keywords: total serum protein, immunoglobulins, dairy cattle.

\footnotetext{
Recibido: 4 de febrero, 2014. Aceptado: 30 de junio, 2014. Inscrito en la Vicerrectoría de Investigación. Proyecto 737-A9-184. Universidad de Costa Rica.

2 Estación Experimental Alfredo Volio Mata. Facultad de Ciencias Agroalimentarias. Universidad de Costa Rica. Costa Rica. juan_arroyo07@ hotmail.com, jorge.elizondosalazar@ucr.ac.cr
} 


\section{INTRODUCCIÓN}

Las terneras de lechería nacen prácticamente sin anticuerpos o inmunoglobulinas (Igs) y dependen de la ingesta de calostro para obtener Igs que las ayuden a protegerse contra enfermedades infecciosas (Sasaki et al., 1983; Nocek et al., 1984). El tracto gastrointestinal de la ternera, está diseñado para permitir, durante las primeras 24 horas de vida, la absorción de moléculas grandes, incluyendo las Igs (Hopkins y Quigley, 1997; Morin et al., 1997). Esto se conoce como transferencia de inmunidad pasiva. Una falla en la transferencia de inmunidad pasiva (FTIP) ocurre cuando una ternera no absorbe una cantidad suficiente de Igs.

Basado en diversas investigaciones, existen cuatro factores que contribuyen a una exitosa transferencia de inmunidad pasiva: alimentar con calostro de una alta concentración de Igs ( $>50 \mathrm{~g} / \mathrm{l})$, suministrar un adecuado volumen de calostro, ofrecer este en las primeras dos horas después del nacimiento, y minimizar la contaminación bacterial del mismo (Stott et al., 1979a, 1979b; Elizondo y Heinrichs, 2009).

Una exitosa transferencia de inmunidad pasiva es importante para los productores ya que se ha demostrado que terneras con una FTIP tienen bajas ganancias de peso, sufren severos episodios de diarrea y tienen mayores tasas de mortalidad (Nocek et al., 1984). Robison et al. (1988) encontraron que terneras con una transferencia inadecuada de inmunidad pasiva, mostraron ganancias de peso reducidas en los primeros meses de vida. Un pobre suministro de calostro es un factor de riesgo para el desarrollo de neumonías y ha sido asociado con altos niveles de mortalidad (Wells et al., 1996; Virtala et al., 1999). Además, la FTIP en terneras afecta la productividad a largo plazo, ya que una baja concentración de Igs ha sido asociada con una disminución en la producción de leche durante la primera y segunda lactancia y con un incremento en el descarte de vacas durante la primera lactancia (DeNise et al., 1989; Faber et al., 2005).

Determinar la concentración de proteína sérica total (PST) por medio de refractometría, es una de las formas más prácticas a nivel de campo para determinar aquellos animales con una FTIP, ya que los mayores constituyentes de las proteínas séricas totales son las inmunoglobulinas provenientes del calostro (Wallace et al., 2006; Trotz-Williams et al., 2008).
En Costa Rica existen pocos estudios científicos concernientes al estado inmunológico de las terneras de lechería. Por esta razón, el objetivo del presente estudio fue determinar por tercer año consecutivo la prevalencia de FTIP en terneras de lechería en la Región Huetar Norte de Costa Rica.

\section{MATERIALES Y MÉTODOS}

\section{Toma de muestras y evaluación de la transferencia de inmunidad pasiva}

Los datos del presente estudio corresponden a medidas de proteína sérica total obtenidas durante el periodo comprendido entre agosto y noviembre del 2012 en veintitrés fincas lecheras de la región Huetar Norte de Costa Rica. En dicho lapso de tiempo, las fincas fueron visitadas semanalmente y se tomaron muestras de sangre por venopunción yugular con el sistema de tubos al vacío sin anticoagulante en 657 hembras con edades entre uno y siete días de edad (Trotz-Williams et al., 2008). De las 657 terneras utilizadas en el estudio, 521 de ellas consumieron calostro por amamantamiento y 136 por medio de chupón. Estas últimas fueron separadas de sus madres antes de que consumieran calostro directamente de ellas. No existió una metodología para la selección de las fincas, prácticamente cualquier lechería que estuviera dispuesta a permitir el sangrado de los animales en la zona de estudio se tomó en cuenta. En general, todos los animales se encontraban bajo sistemas de pastoreo. Las lecherías eran especializadas, es decir el ordeño se hacía de forma mecánica en salas de ordeño. Las razas de las vacas se clasificaron en Holstein, Jersey, cruce Holstein x Jersey y otras (para cualquier raza que no se contempla en ninguna de las categorías anteriores). El tamaño de los hatos osciló entre 40 y 1200 vacas en ordeño.

Las muestras de sangre se manejaron de acuerdo al procedimiento descrito por Johnson et al. (2007), estas fueron refrigeradas durante la noche a $4{ }^{\circ} \mathrm{C}$, posteriormente se centrifugaron a $3000 \mathrm{rpm}$ durante quince minutos para separar la fracción sérica. En seguida, la concentración de PST se determinó utilizando un refractómetro de mano (Atago MasterSur $/ \mathrm{N} \alpha$, Bellevue, WA). Para fines del presente 
estudio, se consideró una falla en la adquisición de inmunidad pasiva cuando la concentración de PST fue menor a 5,5 g/dl (Davis y Drackley, 1998; Donovan et al., 1998; Sánchez et al., 2012; Benavides et al., 2013).

\section{Análisis estadístico}

Los datos se analizaron por medio del procedimiento MIXED de SAS (SAS Institute, 2004) para determinar la significancia de los efectos de la raza de la cría, así como el número de lactancia de la madre y el método de alimentación del calostro, donde el animal se consideró como la variable aleatoria. La comparación entre medias se realizó mediante la prueba de Waller-Duncan $(\mathrm{P}<0,05)$. También se generó estadística descriptiva para determinar la proporción de animales con una FTIP según el número de lactancia de la madre y el tamaño del hato en ordeño. Con el fin de evaluar el efecto del tamaño del hato en ordeño, especialmente al considerar la intensidad de las labores por el tamaño de la explotación, sobre la concentración de PST y el porcentaje de FTIP, las fincas se dividieron en cuatro subgrupos.

\section{RESULTADOS Y DISCUSIÓN}

\section{Concentración de proteína sérica total y falla en la transferencia de inmunidad pasiva}

La concentración de PST en terneras de lechería con edades entre uno y siete días de nacidas varió entre 2,4 y $10,0 \mathrm{~g} / \mathrm{dl}$, con un contenido promedio de $6,2 \mathrm{~g} / \mathrm{dl}$. Considerando una falla en la adquisición de inmunidad pasiva cuando la concentración de PST fue menor a $5,5 \mathrm{~g} / \mathrm{dl}, 44,9 \%(295 / 657)$ de los animales evaluados presentaron niveles inadecuados de inmunidad.

Los rangos obtenidos y la concentración promedio son muy similares a los reportados por Sánchez et al. (2012) y Benavides et al. (2013) en la misma zona de estudio. En el 2012 y 2013 la proporción de animales con una FTIP fue de 31,8 y 43,7\%, respectivamente. Es preocupante que a pesar de que los productores conocen la importancia de un adecuado suministro de calostro, la prevalencia de FTIP en terneras de lechería en la región Huetar Norte de Costa Rica continua siendo muy elevada. Se debe recordar que una transferencia inadecuada de Igs es una condición importante de identificar, ya que las terneras recién nacidas son propensas a infecciones, las cuales pueden llevar a altas tasas de morbilidad y mortalidad (Nocek et al., 1984; Robinson et al., 1988).

Existen básicamente cuatro factores que contribuyen a que los animales adquieran una adecuada transferencia de inmunidad pasiva: alimentar con calostro de alta concentración de Igs (>50 g/l), suministrar un adecuado volumen de calostro, ofrecer este en las primeras dos horas después del nacimiento, y minimizar la contaminación bacterial del mismo (Stott et al., 1979a, 1979b; Elizondo y Heinrichs, 2009).

En los Estados Unidos, se reporta que alrededor de un $35 \%$ de las terneras sufren de FTIP, convirtiéndose en un factor económico importante para los productores de leche (Morein et al., 2007), ya que tienen que invertir importantes cantidades de dinero en el tratamiento de enfermedades causadas por agentes patógenos. En este mismo país se reporta también una mortalidad en terneras en la etapa de pre-destete promedio de 7,9\% y una gran proporción de estas muertes se le atribuyen a una FTIP (NAHMS, 2007).

\section{Raza de la cría}

La raza de la cría, influyó significativamente sobre la concentración de PST en las terneras evaluadas. Los animales provenientes de vacas Jersey y del cruce Holstein $\times$ Jersey, obtuvieron una concentración significativamente mayor a los de la raza Holstein y otras (Cuadro 1).

Cuadro 1. Efecto de la raza de la cría sobre la concentración de proteína sérica total (PST) en 657 terneras entre uno y siete días de edad en veintitrés fincas lecheras de la región Huetar Norte de Costa Rica. 2012.

\begin{tabular}{lrcc}
\hline Raza & \multicolumn{1}{c}{$\mathbf{n}$} & PST $(\mathbf{g} / \mathbf{d l})$ & DE \\
\hline Holstein & 112 & $5,5 \mathrm{~b}$ & 1,0 \\
Holstein x Jersey & 59 & $6,2 \mathrm{a}$ & 1,2 \\
Jersey & 144 & $6,2 \mathrm{a}$ & 1,4 \\
Otra & 342 & $5,4 \mathrm{~b}$ & 1,0 \\
\hline
\end{tabular}

n= número de animales, DE= Desviación estándar.

Diferente letra en una misma columna difieren estadísticamente, $\mathrm{P}<0,05$. 
Sánchez et al. (2012) determinaron que las terneras nacidas de vacas Jersey y del cruce Holstein $\times$ Jersey obtuvieron una concentración de PST significativamente mayor a las de la raza Holstein y otras razas, mientras que Benavides et al. (2013) encontraron que los animales provenientes del cruce Holstein $\times$ Jersey obtuvieron una concentración de PST significativamente mayor que los provenientes de las demás razas.

Una de las razones que podrían explicar esta situación es el tamaño de la cría al nacimiento, ya que los neonatos de la raza Holstein son generalmente de mayor tamaño que las crías de animales Jersey o del cruce Holstein $\times$ Jersey y por lo tanto, pueden presentar un mayor volumen de plasma sanguíneo, lo que implica que requieran de un mayor consumo de Igs para lograr presentar un estado adecuado de inmunidad pasiva.

También hay que considerar que la raza es un factor que afecta el contenido de inmunoglobulinas en el calostro. Muller y Ellinger (1981) reportaron concentraciones de 80,$8 ; 65,7 ; 90,4$ y $55,9 \mathrm{~g} / \mathrm{l}$ de inmunoglobulinas en el calostro de vacas de la raza Ayrshire, Pardo Suizo, Jersey y Holstein, respectivamente. Por esta razón, los terneros nacidos de vacas Holstein, podrían adicionalmente estar consumiendo una menor cantidad de inmunoglobulinas con respecto a las otras razas.

\section{Número de parto de la madre}

El número de parto de la madre es un factor que se ha asociado con el contenido de Igs en el calostro. El calostro de novillas de primer parto suele presentar una concentración de Igs menor al de vacas con más lactancias y a su vez, esta concentración se incrementa conforme aumenta el número de partos (Moore et al., 2005; Gulliksen et al., 2008; Kehoe et al., 2011). Dicho aspecto podría eventualmente afectar la concentración de PST en las crías. En el presente estudio, el número de parto no afectó significativamente $(\mathrm{P}>0,05)$ esta variable. Sin embargo, se observó que las terneras nacidas de animales de tercer parto presentaron una menor proporción de animales con FTIP (40\%), mientras que las terneras nacidas de madres de cuatro partos presentaron la mayor proporción de crías con FTIP (50\%) (Figura 1). Estos resultados difieren de los obtenidos por Sánchez et al. (2012) y Benavides et al.

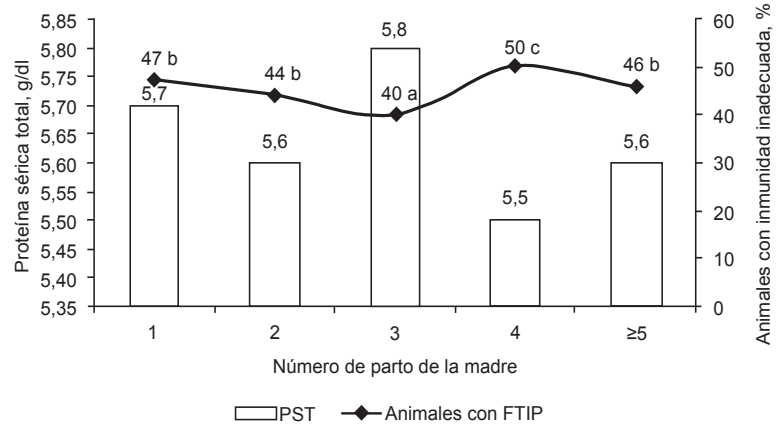

Figura 1. Efecto del número de lactancia de la madre sobre la concentración de proteína sérica total (PST) y la proporción de animales con inmunidad adecuada en 657 terneras entre uno y siete días de edad en veintitrés fincas lecheras de la Región Huetar Norte de Costa Rica. 2012.

Valores con diferente letra difieren estadísticamente, $\mathrm{P}<0,05$.

(2013) ya que en ambos estudios las terneras nacidas de novillas de primer parto presentaron los porcentajes más bajos de FTIP. La diferencia encontrada puede deberse a que en ambos estudios, la concentración de PST en los animales nacidos de novillas de primer parto fue de $6,3 \mathrm{~g} / \mathrm{dl}$, mientras que la determinada en el presente estudio fue de $5,7 \mathrm{~g} / \mathrm{dl}$.

\section{Método de alimentación del calostro}

La concentración de PST varió significativamente $(\mathrm{P}<0,05)$ entre las terneras que permanecieron con la madre y las que fueron alimentadas con chupón. Igualmente la proporción de animales con niveles inadecuados de inmunidad fue significativamente mayor $(\mathrm{P}<0,05)$ cuando estos permanecieron con la madre $(48,8 \%$ vs. $30,1 \%)$, situación que pudo deberse a que las terneras que permanecieron con la madre pudieron haber consumido menos calostro y a un tiempo mayor que las terneras alimentadas con chupón.

Los factores citados anteriormente, pueden ocasionar una pobre absorción de inmunoglobulinas. En este sentido, Besser et al. (1991) y Quigley et al. (1995) demostraron en un experimento que las terneras que permanecieron con la madre después del nacimiento presentaron una menor concentración de PST en comparación con terneras a los que se les ofreció calostro por medio de chupón. 
En un estudio realizado por Elizondo y Rodríguez (2013) en la Región Central de Costa Rica, se determinó que un $30 \%$ de las terneras que consumieron calostro por medio de amamantamiento adquirieron una inmunidad pasiva inadecuada en comparación con solamente un $17 \%$ en terneras que recibieron calostro por medio de chupón.

Se encontró también un efecto significativo entre el número de parto de la madre y el método de alimentación del calostro.Cuando las crías consumieron calostro por medio de chupón, la concentración de PST de las terneras nacidas de animales de primer y segundo parto fue menor en comparación con las crías de vacas con tres o más partos (Cuadro 2). Sin embargo, este efecto no se presentó en los animales que consumieron calostro directamente de sus madres.

Cuadro 2. Efecto del número de parto de la madre y el método de alimentación del calostro sobre la concentración de proteína sérica total (PST) en 657 terneras entre uno y siete días de edad en vientitrés fincas lecheras de la Región Huetar Norte de Costa Rica. 2012.

\begin{tabular}{|c|c|c|c|c|c|c|}
\hline \multirow[b]{2}{*}{ Parto } & \multicolumn{3}{|c|}{ Amamantamiento } & \multicolumn{3}{|c|}{ Chupón } \\
\hline & $\mathbf{n}$ & $\begin{array}{c}\text { PST } \\
(\mathrm{g} / \mathrm{dl})\end{array}$ & DE & $\mathbf{n}$ & $\begin{array}{c}\text { PST } \\
(\mathrm{g} / \mathrm{dl})\end{array}$ & DE \\
\hline 1 & 95 & 5,6 & 1,2 & 23 & $5,9 \mathrm{~b}$ & 1,2 \\
\hline 2 & 133 & 5,6 & 1,2 & 33 & $5,7 \mathrm{~b}$ & 1,1 \\
\hline 3 & 121 & 5,6 & 1,0 & 35 & $6,3 \mathrm{a}$ & 1,5 \\
\hline 4 & 86 & 5,3 & 0,9 & 24 & $6,2 \mathrm{a}$ & 1,7 \\
\hline$\geq 5$ & 86 & 5,5 & 1,2 & 21 & $6,2 \mathrm{a}$ & 1,5 \\
\hline
\end{tabular}

n= número de animales, DE= Desviación estándar.

Diferente letra en una misma columna difieren estadísticamente, $\mathrm{P}<0,05$.

\section{Tamaño del hato}

Con el fin de evaluar el efecto del tamaño del hato en ordeño sobre la concentración de PST y el porcentaje de FTIP, las fincas se dividieron en cuatro subgrupos. Se encontraron diferencias significativas $(\mathrm{P}<0,05)$ entre grupos y se pudo determinar que los animales nacidos en aquellas fincas con menos de 100 y más de 300 animales en ordeño, presentaron la menor concentración de PST $(5,5 \mathrm{~g} / \mathrm{dl})$ y el mayor porcentaje de animales con FTIP (51 y 52\%\%, respectivamente) (Figura 2). Esto se puede deber a una serie de factores, pero de ellos los dos más importantes que tienen que ver con el manejo de los animales son la edad de la ternera en la que se les ofrece la primera toma de calostro y la masa de Igs ingerida.

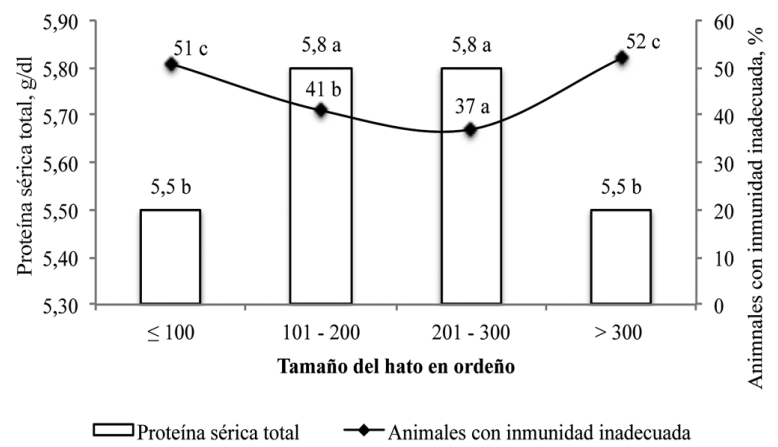

Figura 2. Efecto del tamaño del hato en ordeño sobre la concentración de proteína sérica total y la proporción de animales con inmunidad inadecuada en 657 terneras entre uno y siete días de edad en veintitrés fincas lecheras de la Región Huetar Norte de Costa Rica. 2012.

Valores con diferente letra difieren estadísticamente, $\mathrm{P}<0,05$.

Puede que los animales no consuman calostro durante las primeras horas de vida y/o que la cantidad y calidad ofrecida de este no sea la adecuada. No tener el cuidado de valorar cada uno de estos aspectos, hará que los animales recién nacidos presenten una FTIP, lo que conlleva a consecuencias negativas de salud y desempeño productivo.

En el estudio llevado a cabo por Benavides et al. (2013) se determinó que los animales nacidos en aquellas fincas con más de 300 animales en ordeño presentaron la menor concentración de PST (5,2 g/dl) y el mayor porcentaje de animales con FTIP $(66 \%)$.

Los resultados de PST obtenidos por refractometría en 657 terneras de veintitrés fincas lecheras de la Región Huetar Norte de Costa Rica, indican que el $44,9 \%$ de los animales obtuvieron una inmunidad pasiva inadecuada. Se encontró una asociación significativa entre la concentración de PST y la 
raza de las crías, el número de parto de la madre, el método de alimentación de calostro y el tamaño del hato en ordeño. La prevalencia de la FTIP continúa siendo un problema importante en fincas lecheras de la región Huetar Norte de Costa Rica. Por lo que es necesario establecer prácticas de manejo de calostro que permitan minimizar el riesgo de terneras con una transferencia de inmunidad pasiva inadecuada. Estas prácticas deben incluir al menos: ordeñar el calostro de cada vaca y determinar su calidad por medio de un calostrómetro. En caso de que el calostro tenga una concentración de inmunoglobulinas igual o superior a $50 \mathrm{~g} / 1$, ofrecer como mínimo dos litros de calostro, por medio de chupón o alimentador esofágico, en las primeras dos horas de vida de la ternera y repetir la dosis seis u ocho horas después. En caso de que el calostro sea de mala calidad, es recomendable que previamente se haya almacenado otro de buena calidad en un banco de calostro, de forma que pueda ser descongelado y utilizado en tales situaciones.

\section{AGRADECIMIENTOS}

Los autores desean expresar su más sincero agradecimiento a los dueños de las fincas y a sus colaboradores. El agradecimiento es igualmente extensivo al Programa de Transferencia Tecnológica de la Cooperativa de Productores de Leche Dos Pinos R.L. por la colaboración brindada durante la ejecución de la presente investigación.

\section{LITERATURA CITADA}

Benavides, D., J.A. Elizondo, y G. González. 2013. Estado inmunológico de terneras y terneros de lechería en la región Huetar Norte de Costa Rica. Año II. Agron. Mesoam. 24:285-291.

Besser, T.E., C.C. Gay, y L. Pritchett. 1991. Comparison of three methods of feeding colostrums to dairy calves. J. Am. Vet. Med. Assoc. 198:419-422.

Davis, C.L., y J.K. Drackley. 1998. The development, nutrition, and management of the young calf. Iowa State University Press, Ames, Iowa, USA.

DeNise, S.K., J.D. Robison, G.H. Stott, y D.V. Armstrong. 1989. Effects of passive immunity on subsequent production in dairy heifers. J. Dairy Sci. 72:552-554.
Donovan, G.A., I.R. Dahoo, D.M. Montgomery, y F.L. Bennett. 1998. Associations between passive transfer immunity and morbidity and mortality in dairy heifers in Florida, USA. Prevent. Vet. Med. 34:31-46.

Elizondo, J.A., y A. Heinrichs. 2009. Feeding heat-treated colostrum or unheated colostrum with two different bacterial concentrations to neonatal dairy calves. J. Dairy Sci. 92:4565-4571.

Elizondo, J.A., y J. Rodríguez. 2013. Transferencia de inmunidad pasiva en terneras de lechería que reciben calostro por dos métodos diferentes. Nutr. Anim.Trop. 7:1-13.

Faber, S.N., N.E. Faber, T.C. McCauley, y R.L. AX. 2005. Effects of colostrum ingestion on lactational performance. Professional Anim. Sci. 21:420-425.

Gulliksen, S.M., K.I. Lie, L. Solverod, y O. Osteras. 2008. Risk factors associated with colostrums quality in Norwegian dairy cows. J. Dairy Sci. 91:704-712.

Hopkins, B.A., y J.D. Quigley. 1997. Effects of method of colostrum feeding and colostrum supplementation on concentrations of immunoglobulin $\mathrm{G}$ in the serum of neonatal calves. J. Dairy Sci. 80:979-983.

Johnson, J.L., S.M. Godden, T. Molitor, T. Ames, y D. Hagman. 2007. Effects of feeding heat-treated colostrum on passive transfer of immune and nutritional parameters in neonatal dairy calves. J. Dairy Sci. 90: 5189-5198.

Kehoe, S.I., A.J. Heinrichs, M.L. Moody, C.M. Jones, y M.R. Long. 2011. Comparison of immunoglobulin G concentrations in primiparous and multiparous bovine colostrum. Professional Anim. Sci. 27:176-180.

Moore, M., J.W. Tyler, M. Chigerwe, M.E. Dawes, y J.R. Middleton. 2005. Effect of delayed colostrums collection on colostral IgG concentration in dairy cows. J. Am. Vet. Med. Assoc. 226:1375-1377.

Morein, B., G. Blomquist, y K. Hu. 2007. Immune responsiveness in the neonatal period. J. Comp. Pathol. 137: S27-S31.

Morin, D.E., G.C. McCoy, y W.L. Hurley. 1997. Effects of quality, quantity, and timing of colostrum feeding and addition of dried colostrum supplement on immunoglobulin $\mathrm{G}_{1}$ absorption in Holstein bull calves. J. Dairy Sci. 80:747-753.

Muller,L.D.,y D.K.Ellinger. 1981.Colostral immunoglobulin concentrations among breeds of dairy cattle. J. Dairy Sci. 64:1727-1730.

NAHMS (National Animal Health Monitoring System). 2007. Dairy 2007. Part 1. Reference of dairy health 
and management in the United States. USDA:APHIS Veterinary Services, Ft. Collins, CO, USA.

Nocek, J.E., D.G. Braund, y R.G. Warner. 1984. Influence of neonatal colostrums administration, immunoglobulin, and continued feeding of colostrums on calf gain health, serum protein. J. Dairy Sci. 67:319-333.

Quigley, J.D., K.R. Martin, D.A Bemis, L.N. Potgieter, C.R. Reinemeyer, B.W. Rohrbach, H.H. Dowlen, y K.C. Lamar. 1995. Effects of housing and colostrums feeding on serum immunoglobulins, growth, and fecal scores of Jersey calves. J. Dairy Sci. 78:893-901.

Robison, J.D., G.H. Stott, y S.K. DeNise. 1988. Effects of passive immunity on growth and survival in the dairy heifer. J. Dairy Sci. 71:1283-1287.

Sánchez, J., J.A. Elizondo, y G. Arroyo, G. 2012. Estado inmunológico de terneras y terneros de lechería en la región Huetar Norte de Costa Rica. Año I. Agron. Mesoam. 23:321-327.

Sasaki, M., C.L. Davis, y B.L.Larson. 1983. Immunoglobulin $\mathrm{IgG}_{1}$ metabolism in new born calves. J. Dairy Sci. 60 : 623-626.

SAS Institute. 2004. SAS/STAT 9.1 User's guide. Version 9.1 ed. SAS Institute Inc., Cary, N.C., USA.
Stott, G.H., D.B. Marx, B.E. Menefee, y G.T. Nightengale. 1979a. Colostral immunoglobulin transfer in calves. I. Period of absorption. J. Dairy Sci. 62:1632-1638.

Stott, G.H., D.B. Marx, B.E. Menefee, y G.T. Nightengale. 1979b. Colostral immunoglobulin transfer in calves. II. The rate of absorption. J. Dairy Sci. 62:1766-1773.

Trotz-Williams, L.A., K.E. Leslie, y A.S. Peregrine. 2008. Passive immunity in Ontario dairy calves and investigation of its association with calf management practices. J. Dairy Sci. 91:3840-3849.

Virtala, A.M., Y.T. Grohn, G.D. Mechor, y H.N. Erb. 1999. The effect of maternally derived immunoglobulin $\mathrm{G}$ on the risk of respiratory diseases in heifers during the first 3 months of life. Prevent. Vet. Med. 39:25-37.

Wallace, M.M., B.D. Jarvie, N.R. Perkins, y K.E. Leslie. 2006. A comparison of serum harvesting methods and type of refractometer for determining total solids to estimate failure of passive transfer in calves. Can. Vet. J. 47:573-575.

Wells, S .J., D.A. Dargatz, y S.L. Ott. 1996. Factors associated with mortality to 21 days of life in dairy heifers in the United States. Prevent. Vet. Med. 29:9-19. 
